\title{
Preferential expression of hPGFS in primary SCCHN and tumour cell lines derived from respiratory and digestive organs
}

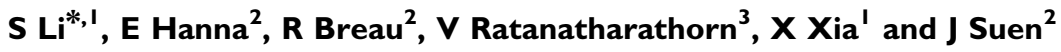 \\ 'Department of Comparative Biomedical Sciences, SVM, Louisiana State University, Skip Bertman Drive, LA 70803, USA; ${ }^{2}$ Department of \\ Otolaryngology/Head and Neck Surgery, University of Arkansas for Medical Sciences, 430I West Markham, Slot 543, Little Rock, AR 72205, USA; \\ ${ }^{3}$ Department of Radiation Oncology, University of Arkansas for Medical Sciences, 430I West Markham, Slot 77I, Little Rock, AR 72205, USA
}

Identifying overexpressed genes in tumours is a critical step for tumour diagnosis, prognosis, and treatment. Using differential display polymerase chain reaction, sequence analysis, and gene Blast searches, we discovered that human prostaglandin F synthase (hPGFS) was upregulated in squamous cell carcinoma of the head and neck (SCCHN). Northern blot analysis indicated that up to a I6-fold increase in the level of hPGFS expression was detected in 40.5\% (I5 out of 37) of SCCHN primary tumours. The increased expression of hPGFS in SCCHN was primarily detected in SCC of larynx and hypopharynx (59\%, P<0.05). Using the same primary tissue samples, increased levels of epidermal growth factor receptor (EGFR) expression were detected in only $32 \%$ of tumour tissues, suggesting hPGFS may have the potential to become a drug target or molecular marker for SCCHN. To determine if the increased level of hPGFS expression came from tumour cells, we determined the level of hPGFS expression in SCCHN tumour cell lines. A high level of hPGFS expression was detected in four out of five tumour SCCHN cell lines. To determine if upregulation of hPGFS is SCCHN-specific, hPGFS expression was analysed in 59 tumour cell lines derived from different types of tumours. The expression of hPGFS was increased from two- to 500-fold in a large portion of cell lines derived from lung (five out of nine), colon (five out of seven) as well as head and neck cancer (four out of five). These data link hPGFS expression to tumours located in the respiratory and digestive organs.

British Journal of Cancer (2004) 90, 1093 - 1099. doi:10.1038/sj.bjc.6601636 www.bjcancer.com

(c) 2004 Cancer Research UK

Keywords: differential display; head and neck cancer; colon cancer; lung cancer, gene expression; hPGFS

Squamous cell carcinoma of the head and neck (SCCHN) is the fourth most common malignancy among males in the US, with more than 40000 cases diagnosed each year. In Europe, 60000 cases are diagnosed yearly, compared to 500000 cases worldwide (Chuaqui et al, 1997; Chan et al, 1998). Only a few biomarkers and therapeutic gene targets are known to display alterations in SCCHN. These include the commonly known markers for other tumours, such as $p 53, p 53 A b, p 16, R b, P T E N, E G F R, b c l 2, p 21$, and VEGF (Koch, 1999). Use of proliferation markers, such as Ki-67, and proliferating cell nuclear antigen for diagnosis of SCCHN has also been attempted, but they are not tumour-specific. To design better strategies for targeting gene therapy, as well as for diagnosis and prognosis, it is important not only to validate the existing genes but also to discover novel genes for SCC (Sehgal et al, 1998). This is also true for other types of tumours.

Since its invention in 1992, the DD technique has evolved into a powerful method for elucidating changes in gene expression in response to disease development and treatment, as well as studying gene functions and cloning novel genes (Liang and Pardee, 1992; Liang et al, 1992; Sun et al 1994; Lehar et al, 1996). Differential display allows the mRNA profile of all genes expressed from two

*Correspondence: S Li; E-mail: sli@vetmed.Isu.edu

Revised 27 October 2003; accepted II December 2003 different samples to be compared side by side, on the same gel, making the simultaneous detection of both up- and downregulated gene expression possible (Liang et al, 1992). This technique has been widely used in studying up- or downregulated genes in many tumour tissues, including prostate, thyroid (Musholt et al, 1997), pancreatic (Ozaki et al, 1998), and breast cancers (Watson and Fleming, 1994), colorectal and oesophageal carcinomas (Graber et al, 1996; Chan et al, 1998), melanoma (Duncan et al, 1998), and glioblastoma (Chuaqui et al, 1997; Sehgal et al, 1997). However, to our knowledge, no study using this technique in primary SCCHN tissues has been performed, although a few studies have reported using mouse or tumour cell lines of SCCHN (Gorogh et al, 1997; Patel et al, 1997; Gottschlich et al, 1999; Dong et al, 2001).

Here, we report the discovery of three genes differentially expressed in SCCHN tissues. The most interesting gene is human lung prostaglandin $\mathrm{F}$ synthase ( $h P G F S$ ) that was increased in more than $59 \%$ of larynx or hypopharynx SCC tumour tissues, compared to matched surgical margins. The increased expression of hPGFS was also detected in most of the tumour cell lines (55-80\%) derived from lung, colon, and head and neck cancer, but in a small portion of tumour cell lines of leukaemia, breast, central nervous system, renal, and ovary cancer. prostaglandin F synthase was not detected in normal mucosal cell lines and melanoma cell lines. Thus, the magnitude of increase in hPGFS expression seems dependent on tumour types. 


\section{MATERIALS AND METHODS}

\section{Cell culture and tissue specimen}

SCCHN cell lines were obtained from the laboratories of Teresa Whiteside, PhD (University of Pittsburgh, PA, USA) and Tom Carey, PhD (University of Michigan, Albany, USA), and Normal mucosal cell lines (NCM356, NCM425, and NCM 469) were obtained from Incell Co, LLC (San Antonio, TX, USA). All cells were grown in AIM-V medium supplemented with $10 \%$ foetal calf serum, except for normal mucosal cell lines, which were grown in a M13 medium (Incell Co., LLC). Normal mucosa, surgical margins, and primary SCC tissues were obtained from 37 patients undergoing surgical resection of previously untreated SCCHN at the University of Arkansas for Medical Sciences (UAMS). After surgical removal, samples were immediately snap-frozen in a liquid nitrogen container. All surgical margins used in this study were determined to be pathologically negative. This protocol was approved by the UAMS Institutional Review Board.

\section{Differential display}

For DD polymerase chain reaction (DD-PCR), normal mucosa, negative surgical margins, and the matching tumour tissues were homogenised with a bead-beater in TRIzol reagent (Life Technologies, Inc., Rockville, MD, USA), as described previously (Li et al, 1999), to extract total RNA. Total RNA $(30 \mu \mathrm{g})$ was treated with $10 \mathrm{U}$ of DNase I (MessageClean Kit, GenHunter Corp., Nashville, $\mathrm{TN}, \mathrm{USA}$ ) for $30 \mathrm{~min}$ at $37^{\circ} \mathrm{C}$ to digest any DNA contaminants. The flow chart for the procedure is outlined in Figure 1. Reverse transcriptase (RT)-PCR was performed using the following oligonucleotide primers: RT primer 5'TTTTTTTTTTTN $3^{\prime}\left(\mathrm{T}_{11} \mathrm{~N}\right.$; $\mathrm{N}=\mathrm{G}, \mathrm{C}, \mathrm{A}$ ) and arbitrary 10-mer primer (AP1-8) (GenHunter Corp., Nashville, TN, USA). Total RNA (200 ng) was reversetranscribed using $50 \mathrm{U}$ of Moloney murine leukaemia virus RT in the presence of one RT primer $\left(\mathrm{T}_{11} \mathrm{~N}\right)$ and $20 \mu \mathrm{mol}$ of deoxyribonucleoside triphosphate (dNTP) for $5 \mathrm{~min}$ at $65^{\circ} \mathrm{C}$, followed by $60 \mathrm{~min}$ at $37^{\circ} \mathrm{C}$. After heat inactivation of the RT at $95^{\circ} \mathrm{C}$ for $5 \mathrm{~min}$ and subsequent cooling to $4^{\circ} \mathrm{C}, 2 \mu \mathrm{l}$ of the cDNA samples were added to $18 \mu \mathrm{l}$ of the PCR reaction mixture, containing $200 \mathrm{~nm}$ of one of the eight arbitrary 10-mer primers AP1-8 and $\mathrm{T}_{11} \mathrm{~N}, 0.2 \mu \mathrm{l}$ of $\alpha^{33} \mathrm{P}$-dATP $\left(2000 \mathrm{Ci} \mathrm{m}^{-1}\right.$; NEN Life Science Products, Inc., Boston, MA, USA), and $0.2 \mu \mathrm{l}$ of Taq DNA polymerase. The PCR parameters during 40 cycles were $94^{\circ} \mathrm{C}$ for $30 \mathrm{~s}, 40^{\circ} \mathrm{C}$ for $2 \mathrm{~min}$, and $72{ }^{\circ} \mathrm{C}$ for $30 \mathrm{~s}$. Finally, the samples were heated to $72^{\circ} \mathrm{C}$ for $5 \mathrm{~min}$ and then cooled to $4{ }^{\circ} \mathrm{C}$. The PCR products were analysed on $6 \%$

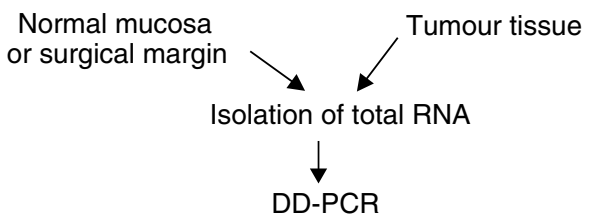

with arbitray and anchor primer

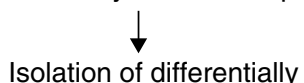

Expressed fragment

and reamplification

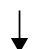

Cycle sequencing of DNA fragments

Blast search and excluding of duplicates

Northern blot confirmation

Figure I Outline of a modified differential display process for isolating differentially expressed genes from SCCHN tissue.
DNA sequencing gels and exposed on an X-ray film. Bands of interest were cut from the dried gels and boiled in a TE (trisEDTA) buffer to extract the DNA. The extracted DNA was further amplified by PCR using the same set of primers. The amplified DNA was subjected to agarose-gel electrophoresis, and the DNA was purified from the gel with the use of a gel extraction kit (Qiagen, Inc., Valencia, CA, USA). The recovered DNA samples were subjected to sequencing with the matching $\mathrm{T}_{11} \mathrm{~N}$ anchoring primer, using a cycle sequence technique in the presence of a radiolabeled terminator (USB Corp., Cleveland, $\mathrm{OH}$, USA). The recovered DNA was also used as template to make probes for Northern blot analysis as described below.

\section{Northern blot analysis}

The technique used for Northern blot analysis was the same as that described previously (Li et al, 1997). The extracted fragments that were amplified by the PCR technique were used as probes for Northern blot analysis. The probes were labelled with $\alpha^{32} \mathrm{P}$-dCTP (3000 Ci mM ${ }^{-1}$, Amersham Pharmacia Biotech, Piscataway, NJ, USA) using Strip-EZ ${ }^{\mathrm{TM}}$ PCR kit (Ambion, Inc., Austin, TX, USA, USA). The RNA of SCCHN and normal mucosal cells were isolated from our own cell culture by the methods described above. Approximately $25 \mu \mathrm{g}$ of total RNA from tissues and $10 \mu \mathrm{g}$ from cell lines were subjected to $1 \%$ agarose-formaldehyde gel electrophoresis at $60 \mathrm{~V}$ for $3 \mathrm{~h}$. The RNA was transferred to a positively charged nylon membrane (Boehringer Mannheim, Indianapolis, IN, USA) and prehybridised and hybridised at $42^{\circ} \mathrm{C}$ in a buffer purchased from Ambion. Hybridisation of the same filters with a probe for $\beta$-actin was used as an internal control for RNA loading, and methylene blue staining was used to determine the relative sizes of hybridised RNA (Li et al, 1997). The Northern blot results were quantified by scanning the expression signal intensity with a PhosphorImager analyser (Model 445 SI, Molecular Dynamics, Sunnyvale, CA, USA).

\section{Statistical analysis of hPGFS expression}

The level of hPGFS expression between normal and tumour tissues of larynx, hypopharynx, or overall sites was determined with paired $t$-test. Statistical significance was defined as a $P<0.05$.

\section{RESULTS}

Determination of the appropriate controls for discovery of novel tumour-related genes using DD-PCR and isolation of SCCHN-related gene fragments

One of the most critical steps in the DD-PCR analysis was the determination of a reliable control. Although this was a difficult task with cultured cell lines, it was even more challenging when primary tumour tissues were used. To determine the appropriate control tissue to perform DD-PCR for isolation of the tumourspecific gene from SCCHN, we tested normal mucosa, skin, and negative surgical margins. Our primary analysis, using $\mathrm{T}_{11} \mathrm{~N}$ $(\mathrm{N}=\mathrm{C}, \mathrm{G}, \mathrm{A})$ and an arbitrary 10 -nucleotide primer, indicated that the expression profile in skin tissue was totally different from the profiles of normal mucosa, the tumour surgical margin, and the tumour. On the other hand, both normal mucosa and negative surgical margins demonstrated a similar gene expression profile (Figure 2A and $\mathrm{B}$ ), indicating either surgical margin or normal mucosa can effectively serve as negative controls for DD-PCR analysis. Thus, both of them were used as controls. Upon comparison of the gene expression profile of tumour tissue with those of surgical margins and normal mucosa, approximately 24 differentially expressed DNA fragments were identified by DDPCR (Figure 2C, Table 1). These DNA fragments were isolated directly from the dried gel as summarised in Table 1. 


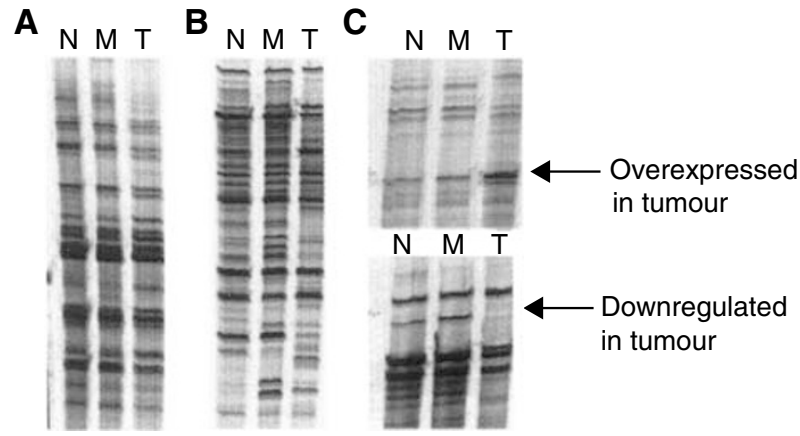

Figure 2 Identification of differentially expressed genes from SCCHN tissue, normal mucosa $(M)$, and negative surgical margin $(N)$ with the use of DD-PCR as described in the Materials and Methods section. (A, B) Autoradiogram of DD-PCR using different $5^{\prime}$ arbitrary 10 -mer primer and one $3^{\prime}$ primer $(T, 1 N)(N=C, G, A)$. (C) Autoradiogram to highlight the gene fragments, which are either overexpressed or downregulated in tumour tissue, cut out of the gel.

\section{Identification of the isolated DNA fragments by sequencing and Northern blot analysis}

We had the option to exclude the false-positive fragments by performing Northern blot analysis, first. Instead, we performed sequence analysis of these fragments because the RNA samples from primary tumour tissues were extremely hard to obtain, and Northern blot analysis needed a relatively large amount of RNA for each gene screening. We found duplicates for five out of 24 fragments, using BLAST search from the gene bank. Another timesaving modification of this procedure was using the isolated DNA fragments for direct sequence analysis instead of cloning prior to sequencing. According to the sequence analysis, the majority of the genes were unknown. The sizes of their cDNA were identified by Northern blot analysis (Table 1), using the isolated DNA fragments as probes. Among the 19 fragments, three were differentially expressed in two separate pairs of tissues used for DD (Figure 3). The rest either showed no change in gene expression or showed change in one pair but not in the other pair of tissues (data not shown). Among the three genes that were differentially expressed on a uniform basis, two were downregulated and one upregulated.

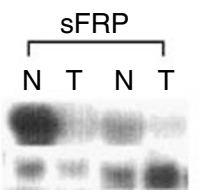

A1-1

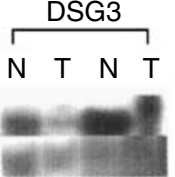

A4-6

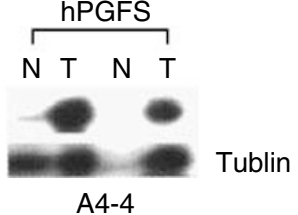

A4-4
Figure 3 Northern blot analysis of three differentially expressed genes in $\mathrm{SCCHN}$ tissues and the matching negative surgical margins. The purpose of this study is to determine the expression of sFRP, DSG3, and hPGFS in two pairs of tumours $(T)$ and negative surgical margins $(N)$. The gene probes were isolated from differential display dried gels, and subjected to sequence analysis. The names of gene fragments were defined by BLAST search from the gene bank at the National Cancer Institute $(\mathrm{NCl})$. Actin was used as an internal control.

The two downregulated genes in tumours were $s F R P$ and desmogelein 3 (DSG3); the upregulated gene was identical to the sequence of $h P G F S$ (Suzuki-Yamamoto et al, 1999) and KIAA0119 (Nagase et al, 1995), according to the BLAST search from gene bank. As downregulation of secreted Frizzled-related protein (sFRP) has been reported to be tumour-related (Finch et al, 1997), we did not further characterise this gene. Since the DSG3 cDNA is $7 \mathrm{~kb}$ and it was difficult to obtain a high-quality Northern blot result from the total RNA isolated from tumour tissues, we plan to characterise it in the future using a different method. A significant difference existed in the level of hPGFS expression between tumour tissues from surgical margins, as determined by Northern blot analysis (Figure 3).

\section{Expression of hPGFS in the SCC primary tissues}

To further demonstrate that hPGFS expression is elevated in SCCHN tumours, we determined the level of hPGFS expression using Northern blot analysis in 37 pairs of SCCHN and surgical margin samples (Table 2). As demonstrated, the level of hPGFS expression was increased in 15 out of 37 SCCHN tumour tissues. Interestingly, the upregulation of hPGFS was detected in 10 out of 17 primary SCC tumours from larynx and hypopharynx (59\%, $P<0.05$ ), but in only a couple of oral SCC (Table 2). Increased expression of hPGFS was independent of tumour stage.

Table I Isolation of tumour-associated genes by DD-PCR and confirmation by Northern blot analysis

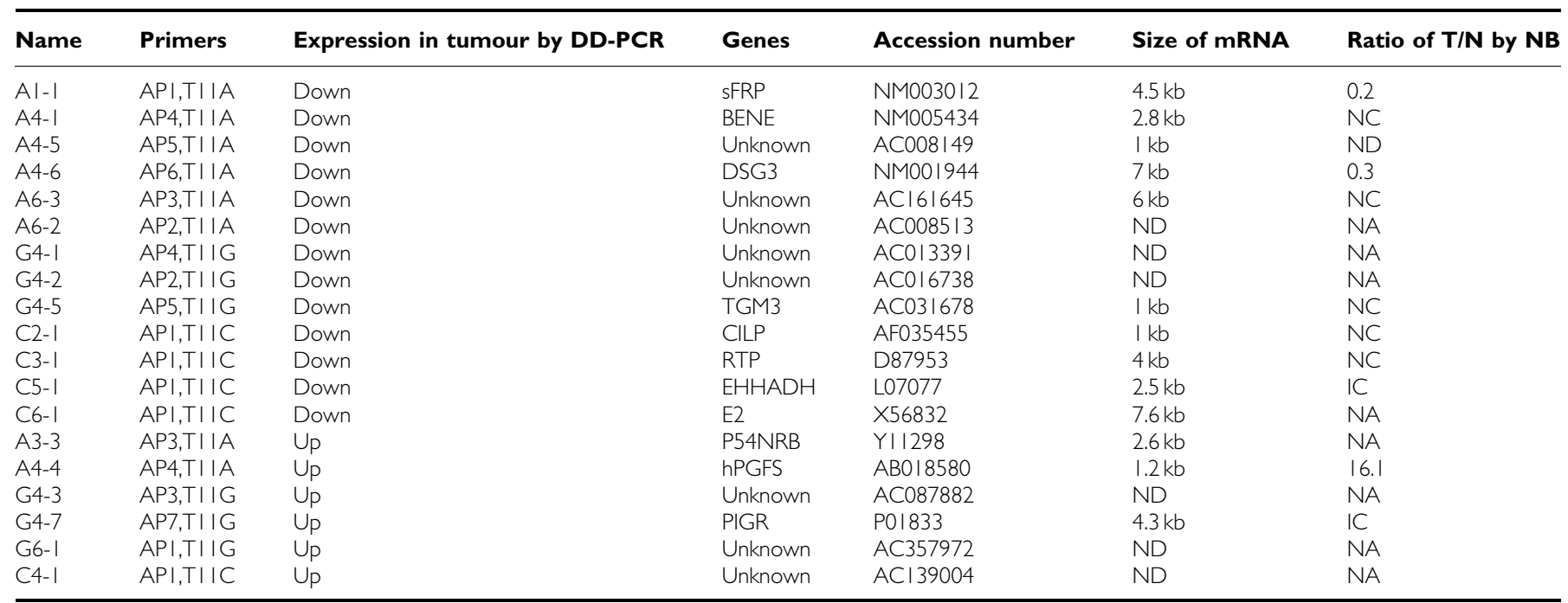

$\mathrm{NB}=$ Northern blot analysis; $\mathrm{T} / \mathrm{N}=$ average expression ratio in two tumours vs in two surgical margins; $\mathrm{ND}=$ not determined; $\mathrm{NC}=$ no change in expression; $\mathrm{IC}=$ inconsistent in expression; NA = not available; DD-PCR = differential display-polymerase chain reaction. 
Table 2 hPGFS and EGFR expression in tumours and surgical margins

\begin{tabular}{|c|c|c|c|c|c|c|}
\hline Samples & $\mathbf{T}$ & $\mathbf{N}$ & $\mathbf{M}$ & Tissue origion & hPGFS (T/N) & EGFR (T/N) \\
\hline$\times 19-2$ & । & $\mathrm{n} / \mathrm{a}$ & 0 & Larynx/glottis & 16 & 2.9 \\
\hline$\times 22-9$ & 4 & $2 b$ & 0 & Oral cavity/FOM-ant & 15 & 5.4 \\
\hline$\times 19-11$ & 2 & $\mathrm{n} / \mathrm{a}$ & 0 & Nasal SCC & 10 & No diff \\
\hline$\times 23-1$ & 1 & $\mathrm{n} / \mathrm{a}$ & 0 & Oral cavity/lateral tongue & 10 & No diff \\
\hline$\times 13-14$ & 3 & 0 & 0 & Larynx/glottis & 9.6 & 1.5 \\
\hline$\times 26-3$ & & & & & 8.4 & 3.3 \\
\hline$\times 16-3$ & 4 & $2 c$ & 0 & Larynx/glottis & 7.3 & 1.6 \\
\hline$\times 14-4$ & 4 & 0 & 0 & Hypo/piri & 7 & No diff \\
\hline$\times 24-9$ & 2 & 0 & 0 & Larynx/supraglottis & 6 & LE \\
\hline$\times 22-8$ & 2 & I & 0 & Hypopharynx/pyriform & 4 & 2.7 \\
\hline$\times 19-14$ & 2 & $\mathrm{n} / \mathrm{a}$ & 0 & Hypopharynx/pyriform & 3.5 & No diff \\
\hline$\times 14-2$ & $4 b$ & 0 & 0 & Maxillary sinus & 2.7 & No diff \\
\hline XI9-1 & 2 & $\mathrm{n} / \mathrm{a}$ & 0 & Larynx/supraglottis & 2.6 & 1.9 \\
\hline$\times 19-7$ & 4 & $2 c$ & 0 & Larynx/supraglottis & 2.2 & No diff \\
\hline$\times 23-3$ & 3 & 3 & 0 & Larynx/glottis & 2 & No diff \\
\hline$\times 14-5$ & 4 & $2 b$ & 0 & Oral cavity/palette & No diff & No diff \\
\hline$X \mid 6-1$ & 3 & $\mathrm{n} / \mathrm{a}$ & 0 & Oral pharynx/bot & No diff & No diff \\
\hline$\times 19-10$ & 4 & $2 b$ & 0 & Oral cavity/FOM & No diff & 0.4 \\
\hline$\times 19-12$ & $\mathrm{n} / \mathrm{a}$ & 1 & 0 & Larynx/glottis & No diff & 1.7 \\
\hline$\times 19-13$ & 1 & $\mathrm{n} / \mathrm{a}$ & 0 & Larynx/glottis & No diff & No diff \\
\hline$\times 19-15$ & 1 & 0 & 0 & Oral cavity/tongue & No diff & No diff \\
\hline$\times 19-3$ & 2 & 0 & 0 & Oral cavity/FOM & No diff & 1.7 \\
\hline$\times 19-4$ & 3 & 0 & 0 & Larynx/glottis & No diff & 2.3 \\
\hline$\times 19-9$ & 4 & $\mathrm{n} / \mathrm{a}$ & 0 & Oral cavity/palette & No diff & No diff \\
\hline$\times 22-4$ & 4 & 3 & & $\mathrm{n} / \mathrm{a}$ & No diff & No diff \\
\hline$\times 22-6$ & 3 & $2 b$ & 0 & Oral cavity/FOM & No diff & No diff \\
\hline$\times 23-10$ & 2 & 0 & 0 & Oral cavity/lateral tongue & No diff & No diff \\
\hline$\times 23-2$ & 3 & 1 & 0 & Oral pharynx/tonsil & No diff & No diff \\
\hline$\times 23-4$ & 2 & 1 & 0 & Oral cavity & No diff & 2.5 \\
\hline$\times 23-5$ & 2 & 3 & 0 & Oral cavity/tongue & No diff & No diff \\
\hline$\times 24-3$ & $\mathrm{n} / \mathrm{a}$ & $\mathrm{n} / \mathrm{a}$ & $\mathrm{n} / \mathrm{a}$ & Oral cavity & No diff & No diff \\
\hline$\times 24-5$ & 2 & $\mathrm{n} / \mathrm{a}$ & $\mathrm{n} / \mathrm{a}$ & Oral cavity & No diff & No diff \\
\hline$\times 24-6$ & 2 & $\mathrm{n} / \mathrm{a}$ & 0 & Paranasalsinus/max & No diff & No diff \\
\hline$\times 24-7$ & 3 & 0 & 0 & Hypopharynx/pyriform & No diff & No diff \\
\hline$\times 26-5$ & & & & & No diff & No diff \\
\hline$\times 24-2$ & $\mathrm{n} / \mathrm{a}$ & $2 b$ & 0 & Larynx/glottis & 0.5 & No diff \\
\hline$\times 26-4$ & $\mathrm{n} / \mathrm{a}$ & $\mathrm{n} / \mathrm{a}$ & $\mathrm{n} / \mathrm{a}$ & $\mathrm{n} / \mathrm{a}$ & 0.1 & 4.4 \\
\hline
\end{tabular}

$\mathrm{T} / \mathrm{N}$, the ratio of gene expression in the tumour vs in the matched surgical margin.

\section{Expression of epidermal growth factor receptor (EGFR) in the primary tissues derived from surgical margins and tumours}

To determine whether the increased level of hPGFS expression correlates to the expression of a well-known tumour marker and drug target, EGFR. The same Northern blot membranes used for analysing hPGFS expression were hybridised with the EGFR probe. As shown in Table 2, 12 out of 37 tumour samples demonstrated more than a 1.5-fold increase in the level of EGFR expression. There is no direct correlation between EGFR and hPGFS expression. However, a high frequency (46.7\%) of elevated expression of EGFR was found in the tumours in which increased expression of hPGFS was also found; a low frequency $(22.7 \%)$ of elevated EGFR expression was found in the tumours in which hPGFS expression was not increased or decreased (Table 3).

\section{Expression of hPGFS was detected primarily in tumour cell lines from respiratory and digestive organs}

To verify that increased expression of hPGFS in primary SCCHN tumours was at least partially due to the increase in tumour-cell expression, we analysed hPGFS expression in five SCCHN cell lines, and 59 tumour cell lines derived from tumours from other organs, including breast, prostate, renal, colon, lung, blood, central nervous system, ovary, and skin. Three normal mucosal cell lines,
NCM356, NCM425, and NCM460, were used to compare the relevant level of hPGFS expression. The expression of hPGFS in tumour cell lines was defined as more than a two-fold increase over the level of the control cell line NCM425. As demonstrated by Northern blot results, in Figure 4 and Table 3, the level of hPGFS was increased 8.6- to 74.5-fold in four out of five cell lines from SCCHN; 2.1- to 105-fold in five out of seven cell lines from colons. Thus, the increased expression of hPGFS detected in tumours (Figure 3, Table 2) was at least partially due to its upregulation in tumour cells (Figure 4, Table 3). Interestingly, hPGFS was not detected in melanoma (zero out of nine) cell lines, but was detected in a small proportion of tumour cell lines derived from breast, central nervous system, ovarian, leukaemia, and renal cancer (Table 3). The magnitude of increase in hPGFS expression in these tumour cell lines was also low. However, hPGFS was significantly increased in tumour cell lines derived from colon cancer, Nonsmall-cell (NSC) lung cancer, head and neck cancer. Up to a 500fold increase of hPGFS expression was detected (Table 3), suggesting that the high level of hPGFS expression was associated with tumour types.

\section{DISCUSSION}

Using a modified DD-PCR technique, in combination with analysis of DNA sequence and gene expression by bioinformatics and 
Table 3 hPGFS expression in tumour cell lines

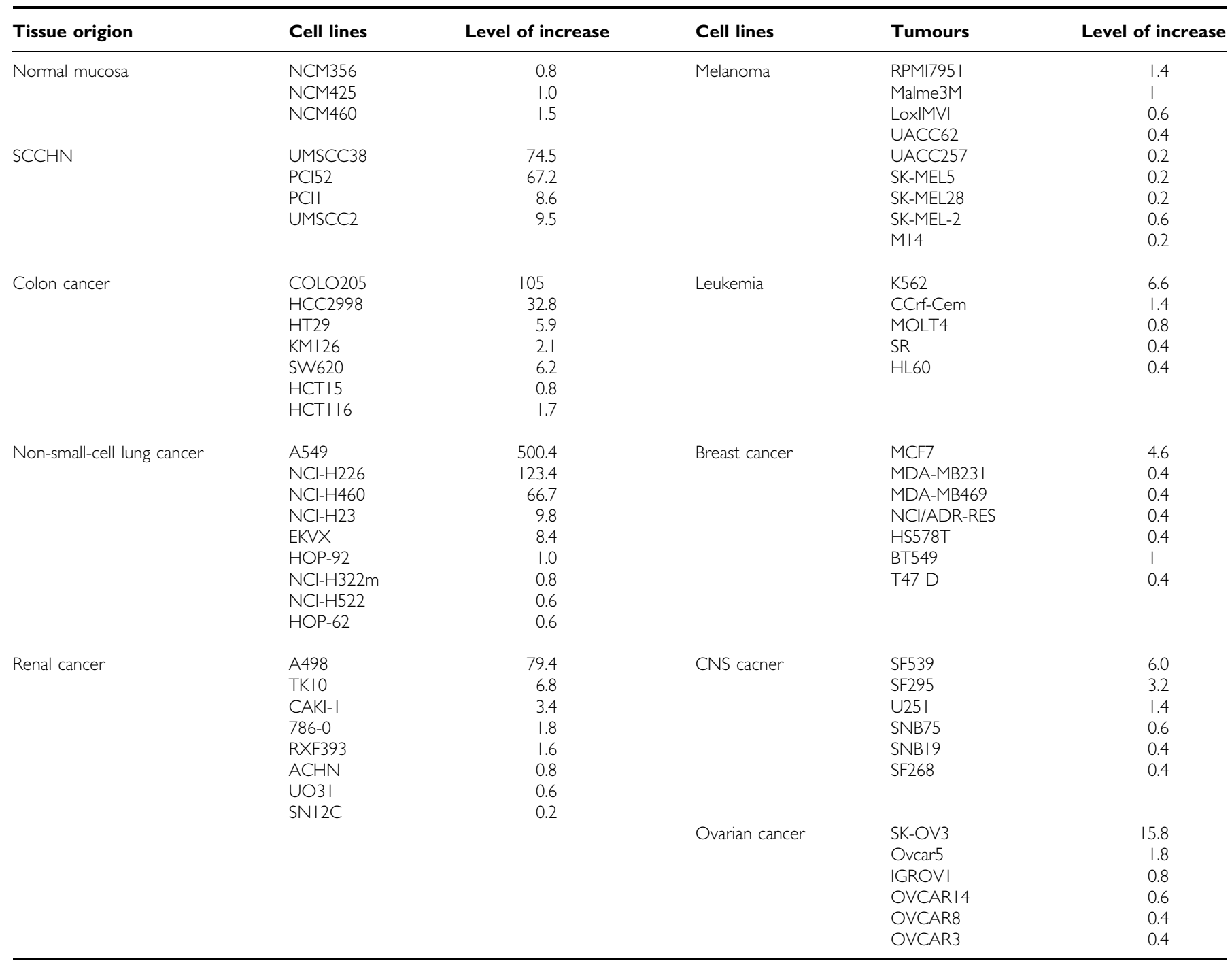

hPGFS expression in different cell lines was normalised from the expression of NCM425, a normal colon mucosa cell line.

A

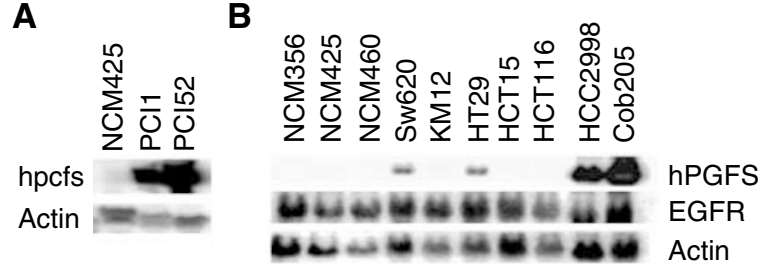

Figure 4 Northern blot analysis of gene expression in cell lines derived from normal mucosa and tumours of SCCHN and colon. NCM356, NCM425 and NCM460 are normal mucosal cell lines. COLO205, HCC2998, HT29, KMI26, SW620, HCTI5 and HCTII6 are colon tumour cell lines. PCl52 and PClI are tumour cell lines of SCCHN. (A) Increased expression of hPGFS in SCCHN tumour cell lines. (B) Elevated expression of hPGFS in colon tumour cell lines. Actin was used as an internal control.

Northern blot respectively, we made two interesting observations. One revelation was the downregulation of an apoptosis candidate gene, $s F R P$, and a tumorigenesis suppressor gene, DSG3, in SCCHN that are also found by other investigators in other tumour tissues (Finch et al, 1997; Zhou et al, 1998), demonstrating that different tumours may share a common molecular mechanism in tumorigenesis. The other was discovering the linkage of increased expression of hPGFS to multiple tumours. The increased expression of hPGFS may link to tumorigenesis and maybe able to serve as a potential molecular marker and drug target as supported by three lines of evidence discussed below.

The first line of evidence came from the biochemical function of hPGFS. $h P G F S$ was cloned from a human lung cDNA library with the use of bovine PGF in 1999. The sequence analysis indicated that this cDNA matched KIAA0119, cloned from the human immature myeloid cell line KG-1 in 1995 (Nagase et al, 1995). Although the biological function of KIAA0119 is not clear, its biochemical function might serve as a steroid dehydrogenase. The deduced amino-acid sequence was identical to that of AKR1C3, except for two amino acids (Khanna et al, 1995). The enzymatic study demonstrated that the natural substrates of hPGFS were PGD2 and PGF2, but not steroid hormones such as dihydrotestosterone, catalysed by AKR1C3 (Suzuki-Yamamoto et al, 1999). It has been known that cyclooxygenase 2 (Cox2) is overexpressed in head and neck tumour tissues, induces tumorigenesis, and modulates the production of PGD2 (Kawamori et al, 1998). Thus, these two enzymes are in the same biochemical pathway and they may coordinate with each other in promoting tumorigenesis by 
promoting production of different PGs. PGs have been known to favour tumorigenesis (Subbaramaiah et al, 1997) through immunosuppression and increasing neovascularisation (Nugent et al, 1996). However, the exact roles of PGFS and PGD2 in tumorigenesis have not been studied yet. The other PGD downstream molecule, PGE, is known to suppress the immune system, which may promote tumorigenesis. We speculate this may also be the case for PGF2.

The second line of evidence to support increased expression of hPGFS is a potential tumour marker and a drug target that came from the wide expression of this gene in tumour cell lines from many different tumour types. Interestingly, the expression of hPGFS was preferentially increased in tumour cell lines derived from tumours located in respiratory and digestive organs. Up to a 500 -fold increase in hPGFS expression was found in the tumour cell lines derived from the colon, lung, head and neck (Table 3). A higher frequency of elevated hPGFS expression in SCCHN tumours, compared to the frequency of increased EGFR expression, was found in this study (Table 2). However, the expression of hPGFS in tumour cell lines of melanoma, central nervous system, leukaemia, breast, renal, and ovarian cancer was either not detected or only modestly increased in a small portion of cell lines examined. Thus, hPGFS may also be a potential drug target for some of the tumours because the huge differential expression between some types of the tumours, in which a high level of expression occurs.

The third line of evidence to support the notion that increased hPGFS expression can be used as a potential molecular marker and a drug target is that hPGFS increased in a large number of primary tumour tissues. As shown in Table 2, hPGFS was increased in 10 out of $17(59 \% P<0.05)$ larynx and hypopharynx SCC compared with negative surgical margins tissues. The overall frequency of elevated hPGFS expression in SCCHN tumours (40.5\%) exceeds the frequency of EGFR (32.4\%), a well-known molecular marker

\section{REFERENCES}

Chan EC, Lue MY, Hsu KC, Fan HA (1998) Identification of novel genes that are differentially expressed in human colorectal carcinoma. Biochem Biophys Acta 1407: 200 - 204

Chuaqui RF, Englert CR, Strup SE, Vocke CD, Zhuang Z, Duray PH, Bostwick DG, Linehan WM, Liotta LA, Emmert-Buck MR (1997) Identification of a novel transcript up-regulated in a clinically aggressive prostate carcinoma. Urology 50: 302-307

Dong G, Loukinova E, Chen Z, Gangi L, Chanturita TI, Liu ET, Van Waes C (2001) Molecular profiling of transformed and metastatic murine squamous carcinoma cells by differential display and cDNA microarray reveals altered expression of multiple genes related to growth, apoptosis, angiogenesis, and the NF-kapaB signal pathway. Cancer Res 61: $4797-4808$

Duncan LM, Deeds J, Hunter J, Shao J, Holmgren LM, Woolf EA, Tepper RI Shyjan AW (1998) Down-regulation of the novel gene melastatin correlates with potential for melanoma metastasis. Cancer Res 58: $1515-1520$

Finch PW, He X, Kelley MJ, Uren A, Schaudies RP, Popescu NC, Rudikoff S, Aaronson SA, Varmus HE, Rubin JS (1997) Purification and molecular cloning of a secreted, frizzled-related antagonist of Wnt action. Proc Natl Acad Sci USA 6770-6775

Gorogh T, Folz BJ, Lippert BM, Gottschlich S, Externbrink J, Niemann AM, Werner JA (1997) Reproducibility of nonradioactive DDRT-PCR method for detection of gene expression in squamous epithelial carcinoma cells of the upper aerodigestive tract. Laryngorhinootologie 76: 42-45

Gottschlich S, Folz BJNiemann AM, Goeroegh T, Werner JA (1999) Differentially expressed genes in head and neck cancer. Laryngoscope 108: $639-644$

Graber MW, Schweinfest CW, Reed CE, Papas TS, Baron PL (1996) Isolation of differentially expressed genes in carcinoma of the esophagus. Ann Surg Oncol 3: 192-197 and drug target for multiple types of tumours. Moreover, these two markers may complement each other to make a better diagnosis than use of a single marker because the elevated expression of these two genes does not occur in the same tumour sample (Table 2). Combining hPGFS with EGFR and other tumour markers will certainly increase the accuracy of molecular diagnosis for specific type of tumours.

The magnitude of increased expression of hPGFS varied among different tumour tissues, despite the use of a consistent sampling procedure. One possibility is the heterogeneity in the tumour tissues from different patients. Microscopic laser capture of tumour-specific cells could avoid this problem, but it was impossible to get enough RNA from each of the 37 tumour tissues for Northern blot analysis. Although the PCRbased quantitation requires a less amount of RNA, the high homology of hPGFS with several other genes such as AKR1C3 (two amino acids difference) hindered this approach. The tissue heterogeneity-caused variation in hPGFS expression can be better examined when an hPGFS-specific antibody becomes commercially available.

In conclusion, this is the first demonstration that hPGFS is differentially expressed mainly in SCC of larynx and hypopharynx, as well as tumour cell lines derived from lung and colon cancer. Therefore, it may be a potential therapeutic target for these cancers.

\section{ACKNOWLEDGEMENTS}

We thank Dr Thomas Carey from University of Michigan and Dr Teresa Whiteside from University of Pittsburgh for providing SCCHN cell lines for this study. This work is partially supported by grants from the NIH (CA98928 and DE14682).
Kawamori T, Rao CV, Seibert K, Reddy BS (1998) Chemopreventive activity of celecoxib, a specific cyclooxygenase- 2 inhibitor, against colon carcinogenesis. Cancer Res 58: 409-412

Khanna M, Qin KN, Wang RW, Cheng KC (1995) Substrate specificity, gene structure, and tissue-specific distribution of multiple human $3 \alpha$ hydroxysteroid dehydrogenases. J Biol Chem 270: 20162-20168

Koch WM (1999) Clinical implications of biomarkers in head, neck cancer. Curr Oncol Rep 1: 129-137

Lehar SM, Nacht M, Jacks T, Vater CA, Chittenden T, Guild BC (1996) Identification and cloning of EI24, a gene induced by $p 53$ in etoposidetreated cells. Oncogene 12: 1181-1187

Li S, Leonard D, Wilkinson MF (1997) T cell receptor (TCR) mini-gene mRNA expression regulated by nonsense codons: a nuclear-associated translation-like mechanism. J Exp Med 185: 985-992

Li S, MacLaughlin FC, Fewell JG, Li Y, Mehta V, French MF, Nordstrom JL, Coleman M, Belagali NS, Schwartz RJ, Smith LC (1999) Increased level and duration of expression in muscle by co-expression of a transactivator. Gene Ther 6: $2005-2011$

Liang P, Averboukh L, Keyomarsi K, Sager R, Pardee AB (1992) Differential display and cloning of messenger RNAs from human breast cancer versus mammary epithelial cells. Cancer Res 52: 6966-6968

Liang P, Pardee AB (1992) Differential display of eukaryotic messenger RNA by means of the polymerase chain reaction. Science 257: 967-971

Musholt TJ, Goodfellow PJ, Scheumann GF, Pichlmayr R, Wells Jr SA, Moley JF (1997) Differential display in primary and metastatic medullary thyroid carcinoma. J Surg Res 69: 94-100

Nagase T, Seki N, Tanaka A, Ishikawa K, Nomura N (1995) Prediction of the coding sequences of unidentified human genes III: the coding sequences of 40 new genes (KIAA0081-KIAA0120) deduced by analysis of cDNA clones from human cell line KG-1. DNA Res 2: 37-43 
Nugent KA, Gureyev TE, Cookson DJ, Paganin D, Barnea Z (1996) Tissue prostaglandin levels in familial adenomatous polyposis patients treated with sulindac. Dis Colon Rectum 39: 659-662

Ozaki K, Nagata M, Suzuki M, Fujiwara T, Miyoshi Y, Ishikawa O, Ohigashi H, Imaoka S, Takahashi E, Nakamura Y (1998) Isolation and characterization of a novel human pancreas-specific gene, pancpin, that is down-regulated in pancreatic cancer cells. Genes Chromosomes Cancer 22: $179-185$

Patel S, Wang FH, Whiteside TL, Kasid U (1997) Identification of seven differentially displayed transcripts in human primary and matched metastatic head and neck squamous cell carcinoma cell lines: implications in metastasis and/or radiation response. Oral Oncol 33: $197-203$

Sehgal A, Boynton AL, Young RF, Vermeulen SS, Yonemura KS, Kohler EP, Aldape HC, Simrell CR, Murphy GP (1998) Cell adhesion molecule NrCAM is over-expressed in human brain tumors. Int J Cancer 76: $451-458$ Sehgal A, Keener C, Boynton AL, Young RF, Vermeulen SS, Yonemura KS, Kohler EP, Aldape HC, Simrell CR, Murphy GP (1997) Isolation and characterization of a novel gene from human glioblastoma multiforme tumor tissue. Int J Cancer 71: 565-572

Subbaramaiah K, Telang N, Bansal MB, Weksler BB, Dannenberg AJ (1997) Inhibition of cyclooxygenase: a novel approach to cancer prevention. Proc Soc Exp Biol Med 216: $201-210$

Sun Y, Hegamyer G, Colburn NH (1994) Molecular cloning of five messenger RNAs differentially expressed in preneoplastic or neoplastic JB6 mouse epidermal cells: one is homologous to human tissue inhibitor of metalloproteinase. Cancer Res 54: 1139-1144

Suzuki-Yamamoto T, Nishizawa M, Fukui M, Okuda-Ashitaka E, Nakajima T, Ito S, Watanabe K (1999) cDNA cloning, expression and characterization of human prostaglandin F synthase. FEBS 462: 335-340

Watson MA, Fleming TP (1994) Isolation of differentially expressed sequence tags from human breast cancer. Cancer Res 54: $4598-4602$

Zhou Z, Wang J, Han X, Zhou J, Linder S (1998) Up-regulation of human secreted frizzled homolog in apoptosis and its down-regulation in breast tumors. Int J Cancer 78: 95 -99 